Information \& Technology | EPEA Switzerland GmbH

\title{
Cradle-to-Cradle principles change how products are designed
}

Industry from the very beginning has treated natural resources as essentially infinit and the world's capacily to same regard. As the economy becomes global, we now understand this is not true the way we make products also should change. EPEA Switzerland has developed 'Reference Model Cradle-toCradle Design Innovations'. for every productingl works industry. It can be used to create products in way which aim to close the loop on the cradle-to-grave economy whether that's by using safe chemicals and materials, or designing products so their resources can be used across multiple lifecycles without los of quality.

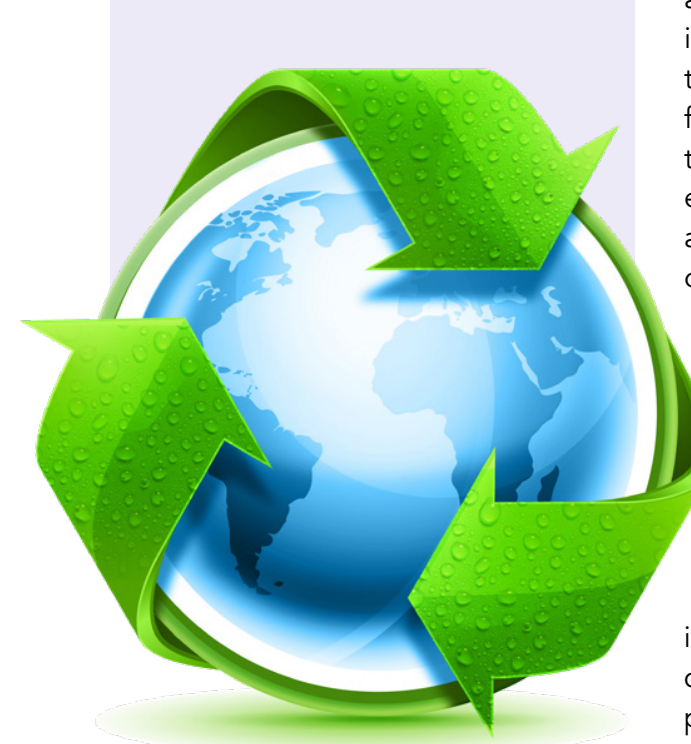

The end of the last decade was a defining moment for
the sustainability movement We, the world's consumers, are more aware than ever of our impact on the environment, and there is and governments to act in the interests of biodiversity and sustainability.

OUR CRADLE-TO-GRAVE ECONOMY The problem is that, for as long as industry has operated, almost all production is conducted on a 'cradle-tograve' process: remove resources from the ground, convert them into products, and expect that products will at the end of their life be entirely discarded - ending up in landfill, recycled or incinerated. Regulations about recycling are leading to some improvement in the way waste is managed, but products are still generally designed ability to biodegrade, or to be reformed into new products. This is especially true for plastics, which are polluting for the same reason they are useful they are resistant to degradation. For example, flexible packaging solutions are saving resources compared to other packaging, but their use of varying multi-layered materials ma it impossible to recycle within a circular economy

Consumers and the environment are crying out for better alternatives to the linear take-make-use-dispose is for companies to ly vald response considering what happens to their products after they are used. Ideally, once a product is discarded, all of its component materials should new products.

A framework for realising this ambition is the cradle-to-cradle approach. chemist Dr Michael Braungart and American architect William McDonough, a properly functioning cradle-to-cradle design process eliminates waste by creating products with materials that are safe, and can be used again in new products. Converting from cradle-tograve to cradle-to-cradle is a difficult but necessary paradigm shift to reach a more circular economy, requiring manufactures to think in cycles rather than in a linear way. We have been educated and trained to think linear. All our systems are based we have to learn to think in cycles.

\section{THE REFERENCE MODEL}

EPEA Switzerland supports companies concepts and was founded in 2009, the founder has over 28 years of experience in cradle-to-cradle product design. EPEA Switzerland is one of 13 firms worldwide which are accredited assessment bodies for the Cradle-to-Cradle Certified' product certification standard.

EPEA Switzerland has created the Cradle-to-Cradle Innovation Reference Model, to make it easier for industry to create products which can meet cradle to-cradle principles. The reference model has 18 steps, many of which purpose of the product. Howning the steps are less obvious because they approach to cradle-to-cradle innovation.

An early stage in the reference model is identifying the type of 'metabolism'. For a material to be used cyclically, it must at some point be metabolised. Some products lend themselves to bein metabolised in biological systems for example, cosmetics and detergents, and products made from natural fibres. All of these can decompose, creating nutrients that can be used to grow plants to make new products. However, some products are not metabolised by nature - things like televisions, cars, and products made from synthetic fibres - these products are instead made from technical nutrints'. It these tochnical nutrients can be separted and reused to make new products. This can work especially well in cases where manufacturers collect used products. so that they can reuse the materials.

The Material Health Assessment approach is, by the Cradle-to-Cradle Certified ${ }^{\text {I't }}$ certification standard, the classification of materials as being $A, B$, $C$ or X materials. ABC-X classification is an efficient method of ensuring that all materials meet the cradle-to-cradle principles of safety and reusability $>100$ ppm. These scientific assessments are subcontracted to accredited Materia Health Assessors of the C2CPII. By legislation industry is required to disclose in the Material Safety Data Sheet (MSDS

EPEA Switzerland has another valuable involvement in the product develo 'knowledge and innovation trustee'. In the complex networks of materia production, some companies may be wary of sharing information about how their manufacturing processes work, including the materials chemicals, colours and suppliers they use. This can make $t$ difficult to assess material for their cradle-to-cradle credentials. EPEA Switzerland can mediate between companies, obtaining relevant information, making an assessment and then passing on the assessment
C $C$ EPEA

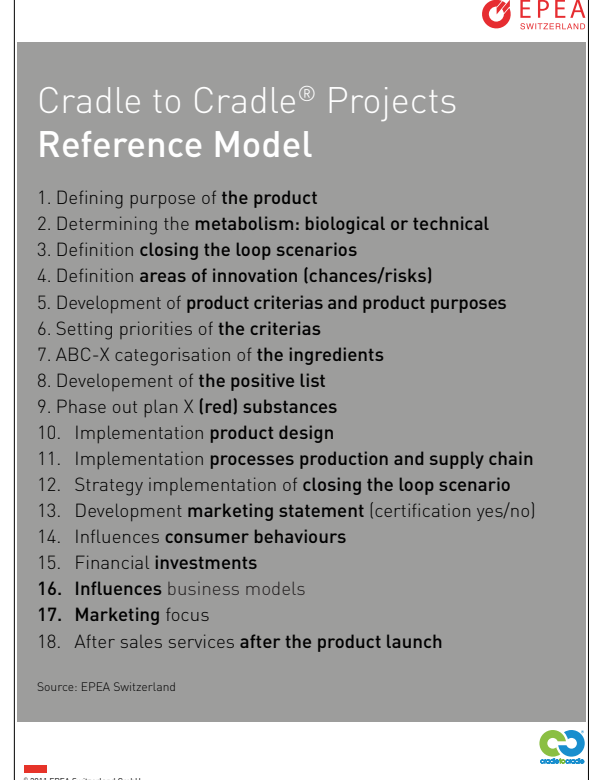

Converting from cradle-to-grave to cradleanufacturers to think in cycles rather than in linear way

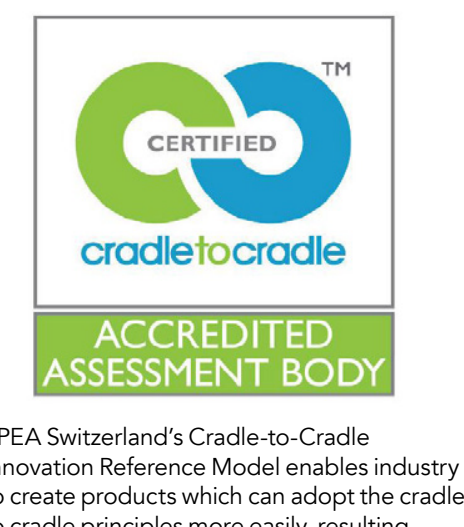

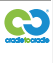
to create products which can adopt the crad a possiblec Cradle-to-Cradle Certified

We have been educated and trained to think linear. All our systems are based on linear design.

Added to this, EPEA Switzerland are an accredited assessment body for the Cradle-to-Cradle Certified'"' certification standard for products of organisations to-Cradle Products Innovation Institute (C2CPII), giving consumers the credibility and knowledge that companies really are acting sustainably.

INDUSTRIAL ROLE MODELS: FLEXIBLE PACKAGINC

to take these principles s company product development?

Since 2011, EPEA Switzerland has been working with German company Werner \& Mertz $\mathrm{GmbH}$, on an ambitious task to mplement the cradle-to-cradle approach into their product and packaging for their .

In 2014, Werner \& Mertz began pitching the idea of a fully recyclable fexible plastic stand-up pouch to packaging suppliers. At that time, many companies dismissed the aspiration and paper company Mackaging companies together with the Duale

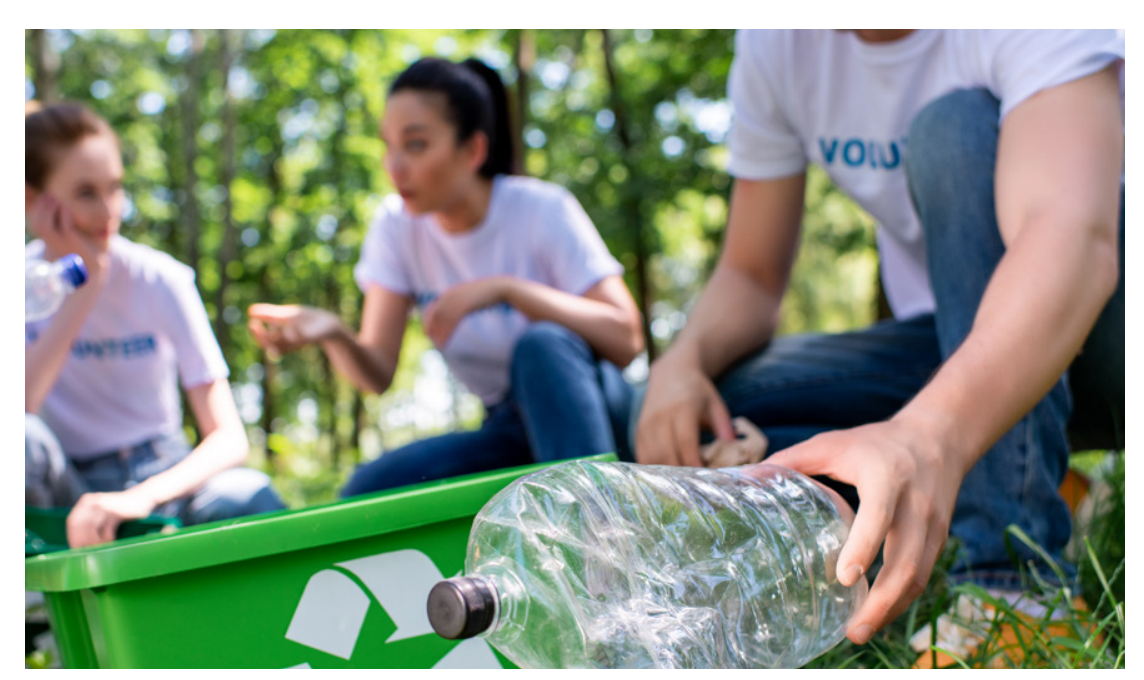




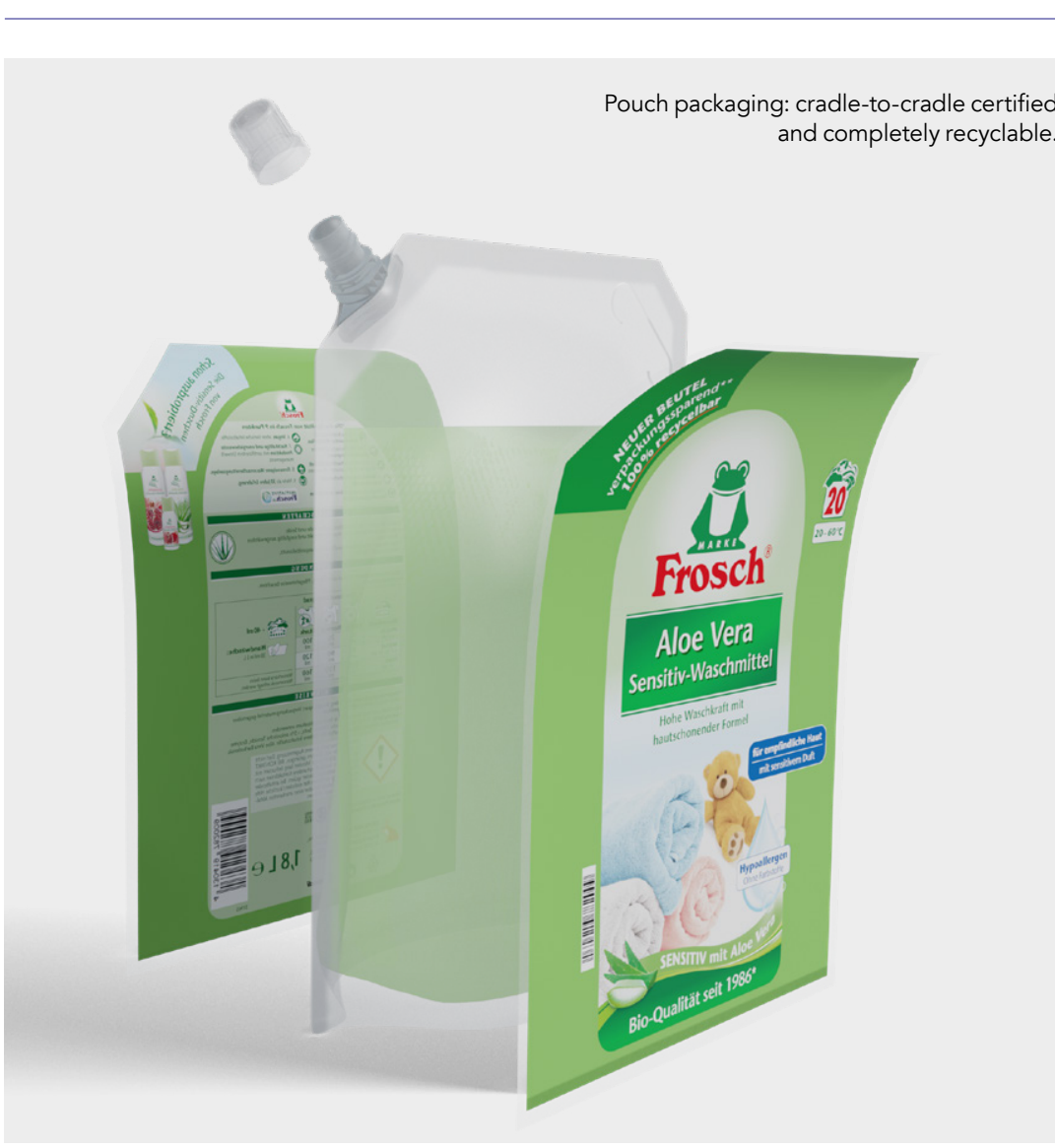

This will add another small piece of the puzzle on how to make the right things right for 'Future viable products designed for a modern society and environment".

System Deutschland "green dot" a recycling specialist, Joachim Christian o-managng director of cyclos-HTP Perform a product design of thed to packasing according to the cradle-tocradle reference model. According to Albin Kälin, CEO of EPEA Switzerland unlike many companies who attempt to implement the cradle-to-cradle approach, the Werner \& Mertz - Mond collaboration was one of the few collaborations to truly 'get it' when it comes to executing a cradle-to-cradle design process.

\section{GETTING THE RIGHT THING RIGHT} Implementing the process properly required these companies to consult with a multitude of sources of expertise for each stage of product development in order to align every aspect of the pouch's design with the why thould technically recylable, but will also

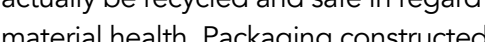
from multiple layers of dfferes tups end up contaminating the waste steam, resulting in materials of a lower grade.
EPEA Switzerland's Albin Kälin explains It is not making a cycle from the lin It just has to be designed out with no compromise. This means all products need a redesign 'rethinking the way we make things'."

As Albin Kälin explains: "This will add another small piece of the puzzle on how to make the right things right for 'future viable products designed for a modern society and environment'."

The end result is a pouch which can be cradle-to-cradle certified and is completely recyclable. Almost all of the packaging is undyed low-density polyethyon, LDP. This includes the body of the pouch, the spout and the cap are found on two panels, also made from LDPE, which attach to the front and back of the pouch without using any glues. These panels are used to advertise the product, as well as contain any additional product information required for customers. Most importantly, the pouch's panels are easy for the recycling machines to unstick, making for easy sorting that doesn't degrade the quality of equivalent quality to the plastic entering the recycling stream is an essential step in creating a circular economy. What's more, it only uses about 30 percent of the material needed to make a rigid plastic bottle of the same volume.

Eventually, companies in every industry der how they can create to secure our future on this planet.

Companies with this vision would do well to emulate the best practise laid out by Werner \& Mertz and Mondi, who have demonstrated how, when taken seriously, the cradle-to-cradle design approach is effective at creating products which are good for people and for the planet.

Cradle-to-Cradle ${ }^{\oplus}$ is a trademark of MBDC MCDonough Braungart Design Chemistry.

Cradle-to-Cradle Certified"' is a certification mark exclusively licensed by the Cradle-to-Cradl.

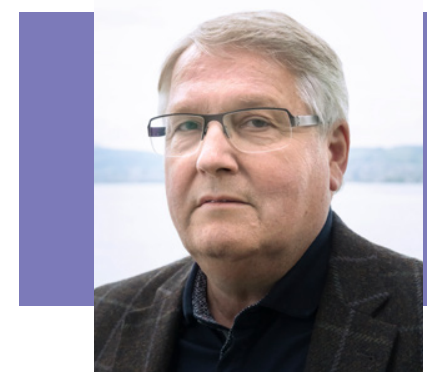

\section{Behind the Research}

\section{Albin Kälin}

E: kaelin@epeaswitzerland.com T: +41764422668 W: www.epeaswitzerland.com Thttps://business.facebook.com/epeaswitzerland/ htps://witer.com/epeaswitzerland 0 https:/Nww.instagram.com/epeaswitzerland/ the recycled plastic - creating plastics of

Research Objectives

EPEA Switzerland, accredited assessment body for the a worldwide management network, independent, neutra Ownership 100\% Albin Kälin GmbH. reas of activities in the development and implementation of Cradle-to-Cradle ${ }^{\oplus}$ design concepts.

\section{Personal Response} of plastic are tricky to process, and may point of the value chain." was finding materials which are not on Cradle-to-Cradle Certfied certification, acting globally wi

EPEA Switzerland GmbH supports

What can companies learn from the way Mondi and ried out their cradle-to-cradle design proces

II "Sustainable development is not a 'plug-and play" and accept that risk is a necessary condition for serious technological advancement. If you want to develop something new, you have to be willing to put in hard work, to take the hurdles of 'restrictive thinking'. for Werner \& Mertz

"We worked our way through an innovation funnel "esting different materials until we arrived at a designed-

Jens Kösters, manager technical services for Mond Consumer Flexibles

"What made this project exceptional was how al relevant parties were involved from the beginning the brand owner, the packaging producer, the waste me $\mathrm{C} 2 \mathrm{CC}$ the product development process"

"One key approach is to close the circle so that packaging can be turned back into high-performance packaging again. The $\mathrm{C} 2 \mathrm{C}$ approach is a vital step
toward saving resources and reducing unnecessary

- Kalin, A. (2016). Flexible packaging industry. Packing

Films, 7(3), 46 - 47.

- Introducing the frog prince of packaging? (2018)

Packaging Europe. Volume 13.6, 4-9.

Packaging Europe (2018). 'Reverse-Engineering' (Pacecy packagingeurope.com/everse-engineering-the-recycling process R. (2019). P

Plastics Engineering. New MonoPrinciples. January 2019, Follows Cradle-to-Cradle plasticsengineering.org

Detail

Albin Kälin

EPEA Switzerland GmbH

Seestrasse 119

CH-8806 Bäch, Switzerland

In 2001, Albin Kälin was awarded with the UBS Key Trophy as "Rhine Valley Entrepreneur of the Year". Between 1981 to 2004 he was Managing Director of Rohner Textil AG in Switzerland. Under his leadership, the company won 19 international design line Climate $x^{\oplus}$ and thus the first Cradle to worldwide in 1993. He was CEO of EPEA Internationale

Umweltforschung GmbH in Hamburg between 2005 to 2009 and additional CEO of EPEA Netherland in 2007-2009. Albin the Cradle-to-Cradle Certified'"' certification standard in 2009 where he is $C E O$.

and Michael Braungart (Founders of Cradle-to-Cradle)

- Reinhard Schneider, Werner \& Mertz GmbH - Immo Sander, Werner \& Mertz GmbH

- Matthias Perrick, Mondi Group

- Jens Kosters, manager technical services for Mondi Consumer Flexibles

based Der Grüne Punkt

"This project is a lighthouse for all industries for how

II

\section{References} Kälin founded EPEA Switzerland GmbH, accredited assessor for

Albin Kälin CEO of EPEA Switzerland
Joachim Christiani, cyclos-HTP

Drer

DrMichael Heyde, DSD, der grüne Punkt 